\title{
BREATHING PROTECTION EQUIPMENT CONSUMPTION: CONTRIBUTION FROM AN EXPERIMENTAL PROTOCOL
}

\author{
C. CORRÊA ${ }^{1}$, A. S. CASTRO ${ }^{1 *}$, A. FALCÃO ${ }^{1}$, G. C. BRAGA ${ }^{2}$, J. J. R. SILVA ${ }^{3}$ and T. A. C. PIRES ${ }^{3}$ \\ ${ }^{1}$ Corpo de Bombeiros Militar de Pernambuco \\ ${ }^{2}$ Corpo de Bombeiros Militar do Distrito Federal \\ ${ }^{3}$ Universidade Federal de Pernambuco \\ cristianocorreacbmpe@gmail.com*
}

Article received in August/2015 and accepted on September/2015

DOI: $10.15628 /$ holos.2015.3314

\section{ABSTRACT}

This article presents an experimental protocol for calculatingthe breathable air consumption on OpenCircuit Self-Contained Breathing Apparatus (SCBA) used by firefighters during operations in smoke environment, especially in firefighting operations. The actual protocol is based on particularities forvaried Fire Departments. Even though the Fire Departments are similar in their activities and collaborative spirit, each institution has different equipment, works under a specific ambient temperature, and has peculiar training programs, representing a unique organism. Creating a simple protocol makes it possible to be easily repeated, establishing, that way, the air consumption during SCBAuse by any Fire Department. One case study in a significant sample of on Battalion of Recife - PE, Brazil, will be presented, creating a reference of air consumption for firefighters during low, middle and high effort during firefighting.

KEYWORDS: Breathing Protection Equipment, Firemen Corporation, Autonomic Mask Consumption. 


\section{INTRODUCTION}

For long in our human development history, controlling fire was considered one of our biggest technological innovations. However, from the moment this "glowing marvel" gets out of human control, our species quickly and violently feels the real power of fire.

The firefighting starts in ancient times and it endure until our days, guiding the most traditional task of firefighters in Brazil and around the world. [1].

This activity is preceded by specific and more increasingly sophisticated technologies and equipment. Among them, the turnout gear that protects the firefighters'body is noteworthy, makingit possible to get into heat environments and endure temperatures that wouldn't be accessible without it, as well as, the breathing protection equipment. [2].

The expression "breathing protection equipment" is much wider, containing also every kind of masks and protection accessories that garnish the breathing apparatus. However, practice inside the Fire Departments in Brazil has made it as synonymous of Self-Contained Breathing Apparatus (SCBA). [3].

SCBAsare fundamental for activities in environments where smoke and some times un known toxic gases fill a considerable part of the environment. The SCBA makesit possible for the firefighters to breathe atmospheric air contained in acompressed air cylinder through pressurereducing valves in a convenient ergonomic structured facial mask.

The necessary amount of the compressed air contained in the cylinder has been, for a long time, a source of debate, since it's impossible to stay inside fire and toxic environment without it $[4,5]$. For this particular argument, the calculations that foresee the user's time autonomy are related to the cylinder's volume, the pressure it was put in, and the values of air consumption estimated for a firefighter at work, usually known as three constants: low/light, middle/moderate and high/heavy.

For each of the three effort categories (low, middle and high), average air consumptions were established through practice exercises that put the firefighters in activities that simulated such efforts. After each test involving a wide range of firefighters, an average result was extracted and used as reference base to calculate the amount of usage time for that particular rate of work.

This article intends to discuss an experimental protocol in which these average consumptions can be asserted in a simple and practical way, offering values that are as close as possible to the local reality, considering that training, equipment, weather, biotypes, age average, gender, and so many other variables are different in many Fire Departments a round the world, or even in Brazil.

\section{EXPERIMENTAL PROTOCOL}

The following protocol was established based on a few preliminary exercises as well as the biography references. [6, 7, 8 and 9] 


\subsection{Protocol Phases}

- Measurement of the firefighter's weight (in kilograms) with and without the full gear, which includes the complete turnout gear, boots, helmet, balaclava and gloves, as well as the SCABA used by the department.

The following graph shows the percent of weight increase created by the full gear in the six groups of firefighters ( 02 female and 04 male).

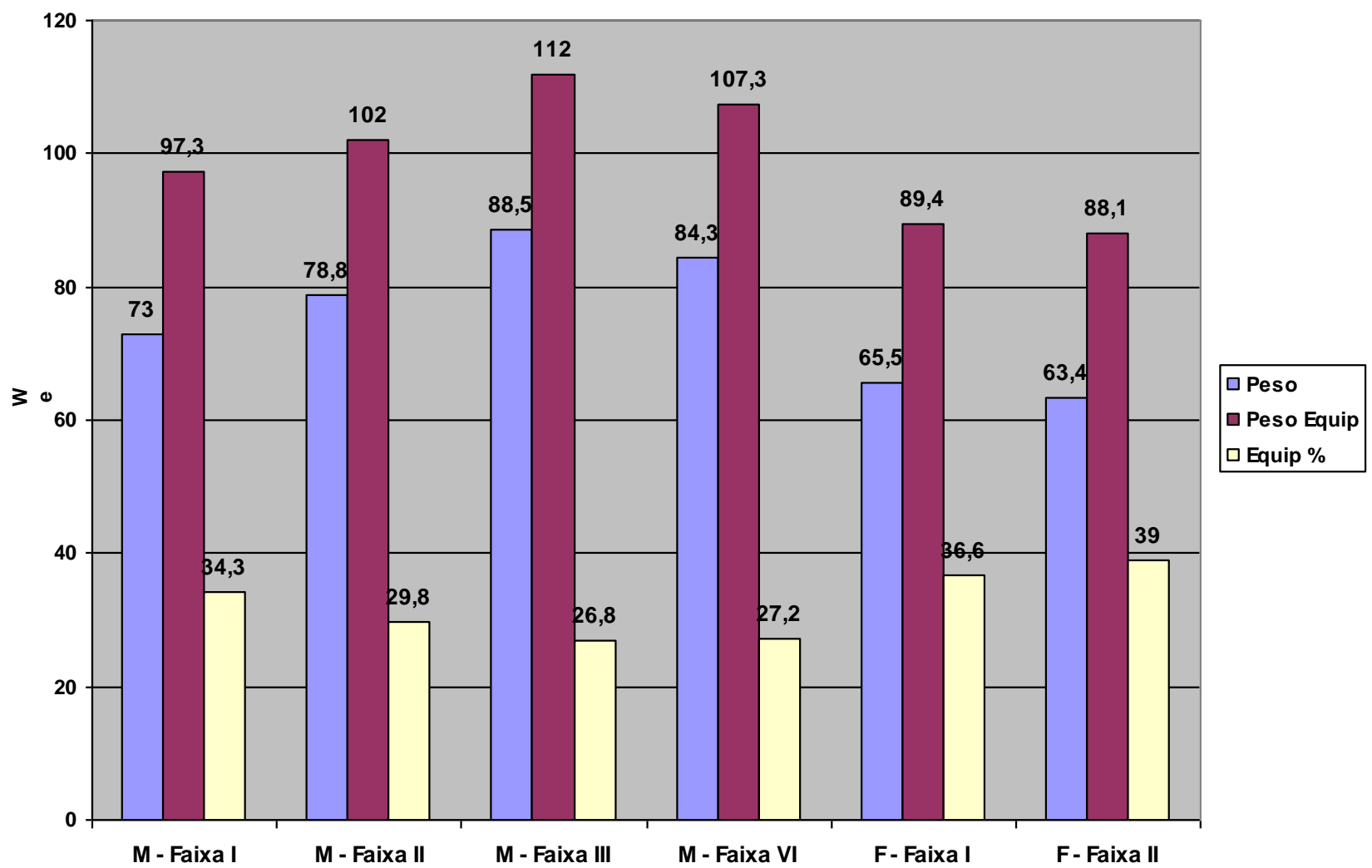

Picture 1 - Chart of average weight(in kg) of the firefighter groups (M-Male and F-Female) with and without the full gear for each age group.

- Measurement of the initial body temperature, using an European certified (CE 0197) skin thermometer, used by direct contact with the firefighters forehead;

- Measurement of the cylinder's pressure using the pressure gauge of the SCBA, and the initial heart rate using a heart rate monitor used by the firefighter during the test;

- Periodic measurement of the cylinder's pressure and the firefighters' heart rate made every two minutes during low and medium effort categories, and every minute during the high effort category;

- Measurement of final pressure and heart rate (pressure gauge and heart rate monitor);

- Measurement of the final temperature using the skin thermometer;

- Twenty minutes recovering period before the beginning of the next exercise set. 


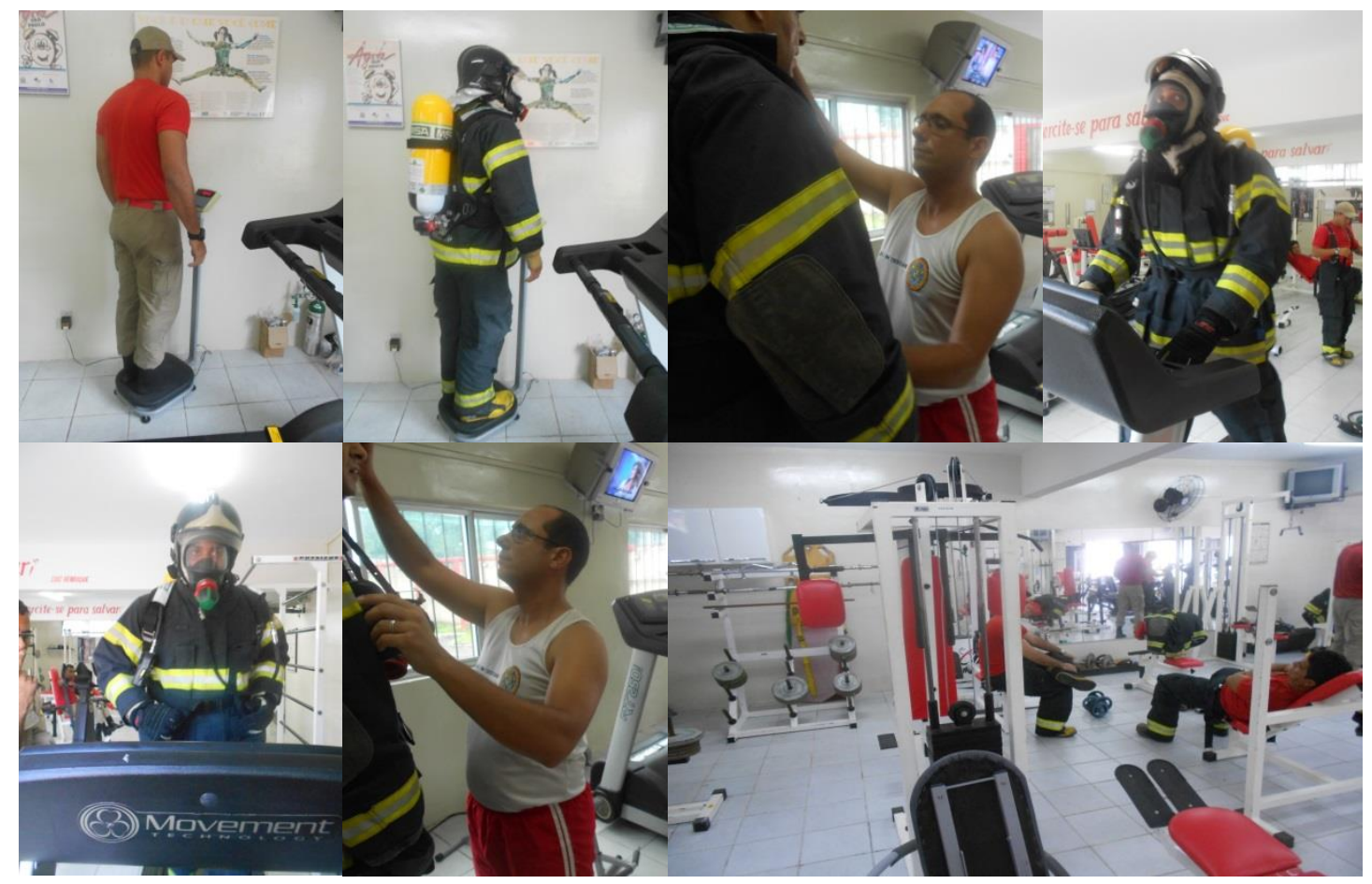

Picture2 - Images of the Experimental Protocol Phases.

All the above phases were realized at the three effort levels (low, medium and high), continually throughout the same day. Such efforts have been established as follows:

Low or light effort: once equipped and monitored, the firefighter walks on the treadmill without any slope $\left(0^{\circ}\right)$ for 10 (ten) minute sat speed of $4 \mathrm{~km} / \mathrm{h}$ (four kilometers per hour).

Medium or moderate effort: like the previous situation and after a 20-minuterecovering period, the firefighter walks/runs on the treadmill without any slope $\left(0^{\circ}\right)$ for 8 (eight) minutes at speed of $6 \mathrm{~km} / \mathrm{h}$ (six kilometers per hour).

High or heavy effort: like the previous situation and after a 20-minuterecovering period, the fireman runs on the treadmill without any slope $\left(0^{\circ}\right)$ for $6(\operatorname{six})$ minutes, at speed of $8 \mathrm{~km} / \mathrm{h}$ (eight kilometers per hour).

\subsection{Safety Procedures}

During any phase of the test the firefighter could request an interruption by raising his right hand, as previously agreed, which would be immediately done. If the heart rate gets reached critical values, the research team would interrupt the test even if the firefighter was willing to continue. 


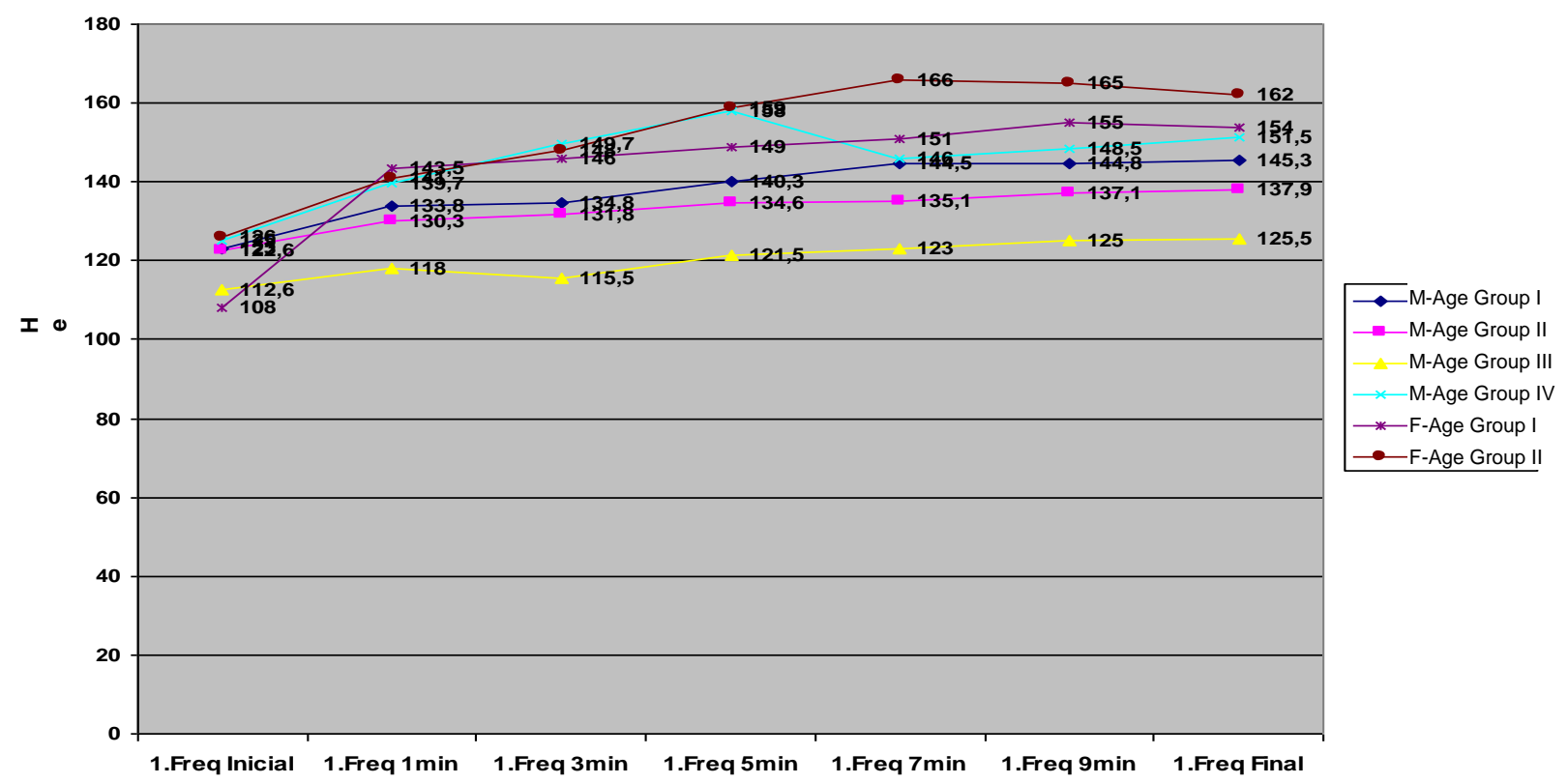

Picture 3 - Chart for the heart rate average, separated by gender and age, during low effort (4 km/h).

One external automatic defibrillator was put next to the treadmill where the tests were being taken in case of an emergency, as well as a medical kit with other emergency medical equipment. There was no need to use any of this equipment during the, although they were kept there as a preventive measure.

\subsection{Equipment used during the tests}

During the tests, besides the full gear, a skin thermometer, a heart rate monitor, a digital scale, a treadmill, and a SCBA were used.

The SCBA used in theseexperiments was the MSA model BD 2100 Max, with a 9-liter capacity cylinder, as shown in the picture below:

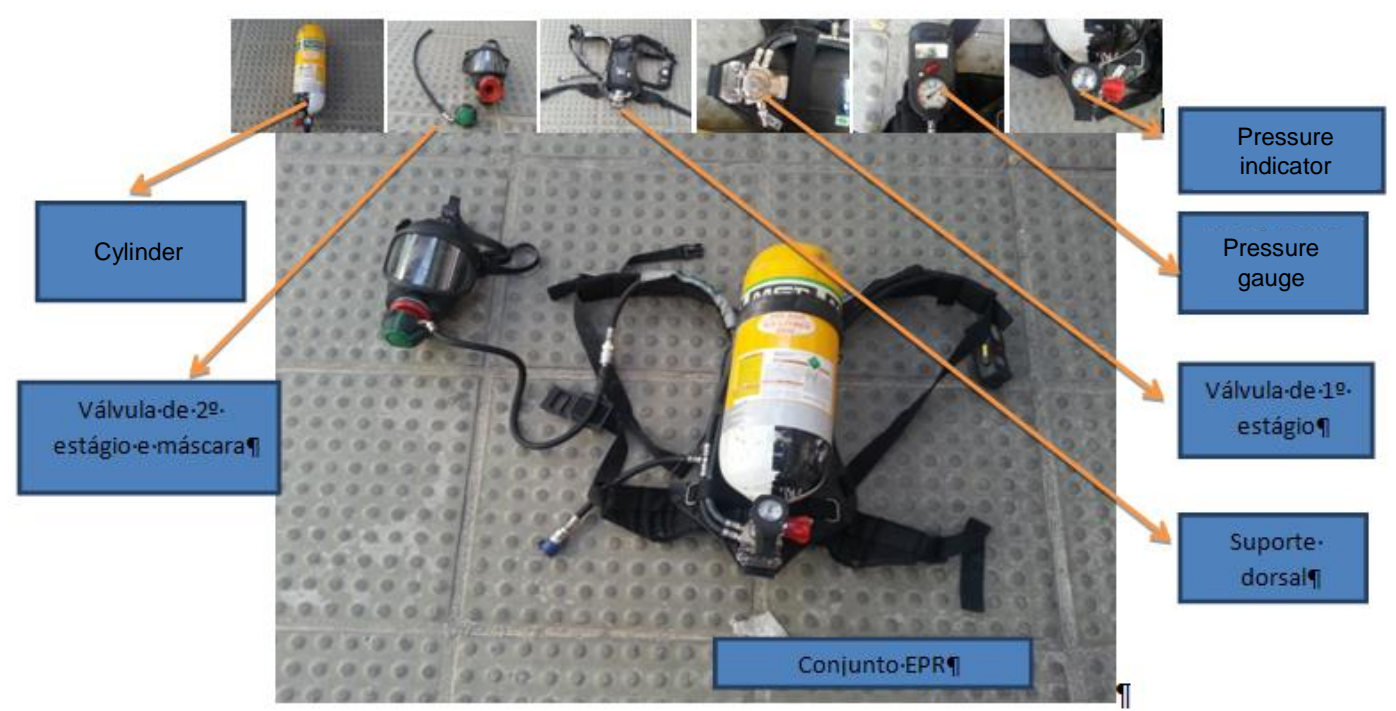

Picture 4-MSA SCBA used in this study 


\section{RESULTS}

The preliminary results discussed here were established by group ages that vary by gender and for every ten years. The group sample was selected by keeping the proportion of age and gender for the whole staff of workers of the $1^{\text {st }}$ Firefighters Brigade $-1^{\circ} \mathrm{Gl}$, during a ten-day period. [10].

There were a total of 33 firefighters tested according to the following age and gender:

\section{Table1- PERCENTUALS OF AGE AND GENDER $1^{\circ} \mathrm{GI}$}

(Reference Date: July, $1^{\text {st }}$ 2013)

\begin{tabular}{lcc}
\multicolumn{1}{c}{ AGE AND GENDER } & PERCENTUAL IN THE SAMPLE & NUMBER \\
Male Age Group I(18 - 27 years old) & $12.1 \%$ & 04 \\
Male Age Group II(28 - 37 years old) & $45.5 \%$ & 15 \\
Male Age Group III(38 - 47 years old) & $24.2 \%$ & 08 \\
Male Age Group IV(above 47 years old) & $09.1 \%$ & 03 \\
Female Age Group I(18 - 27 years old) & $06.1 \%$ & 02 \\
Female Age Group I(28 - 37 years old) & $03.0 \%$ & 01 \\
& Total & 33 Firefighters
\end{tabular}

Source: Sample determinate by the authors, from the service turns between March, $10^{\text {th }}$ and $20^{\text {th }} 2013$.

\subsection{Average consumption calculations}

The calculations that foresee the user's time autonomy are related to the cylinder's volume, the pressure it was put in, and the values of air consumption estimated for a firefighter at work, usually known as three constants: low/light, middle/moderate and high/heavy

The first two values, cylinder's pressure and volume, do not require much discussion for those who need the SCBA, since they can be measured easily. The quantity of air inside of the cylinder can be calculated by the following equation:

$$
\mathbf{P} \cdot \mathbf{V}=\mathbf{Q}^{*}
$$

where: $\mathrm{P}$ is the pressure;

$V$ is the internal volume of the Cylinder

$Q$ is the amount of air contained in the Cylinder

* For firefighters purpose, this calculated pressure is the total pressure of the pressure gauge, after subtracting the reserve pressure, usually established as 50 BAR, defined for leaving the fire scene safely.

The third value, or better yet, the third values, considering the three effort categories (low, medium and high) were established through practice exercises that put the firefighters in activities that simulated such efforts. After each test involving a wide range of firefighters, an average result was extracted and used as reference base to calculate the amount of usage time for that particular rate of work, explained by the following equation:

$$
\mathbf{T}=\mathbf{Q} / \mathbf{C m}
$$

Where: $T$ is the total work time, in minutes;

$Q$ is the amount of available breathable air, in litters, contained in the cylinder;

$\mathrm{Cm}$ is the average firefighter consumption of air for a particular effort category, measured in litters/minute. 
Data was taken for the firefighters that were put through the tests, more specifically their initial and final temperature, weight with and without the full gear, and more importantly, their air consumption during each category (low, medium, and high exercise). An arithmetic average was drawn to show a panoramic view of their consumption grouped by age and gender.

Once the averages for each age and gender group (for each of the three phases of the tests) were calculated, the statistical mode was used [10] to determine the average consumption for the $1^{\text {st }}$ Fire Brigade firefighters, which considers the percent value of each sample group composition.

Those calculated values are surprisingly similar to other tests [7,9], even though they followed different protocols.

The final research results are presented in the table:

Table 2- AVERAGE CONSUMPTION CALCULATIONS

AVERAGE CONSUMPTION (Cruzber Statistic)[10]

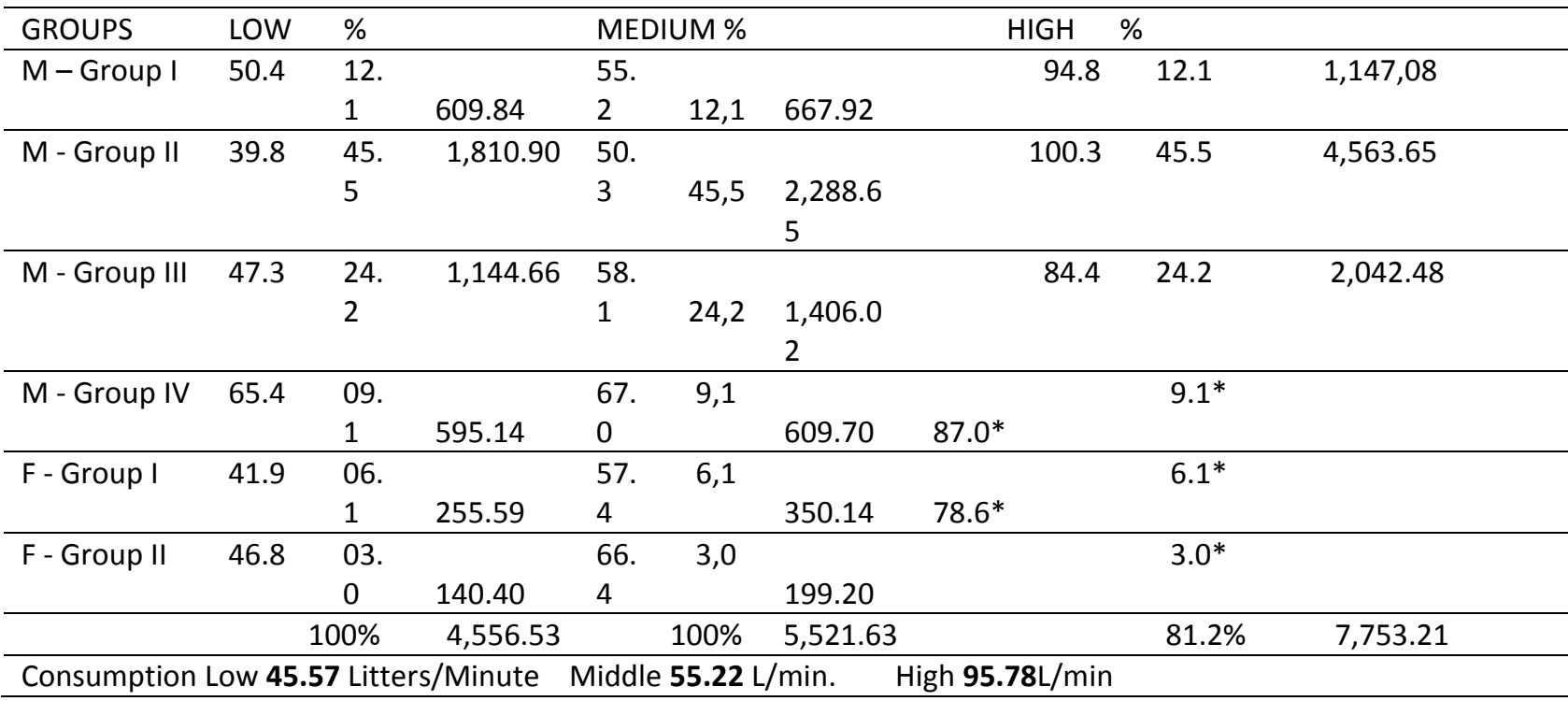

Based on the tests results, the Pernambuco Fire Department has established its firefighter's consumption parameters to be: $45.57 \mathrm{l} / \mathrm{m}$ (liters per minute) for light activities, $55.22 \mathrm{l} / \mathrm{m}$ for moderate activities, and $95.78 \mathrm{l} / \mathrm{m}$ for heavy activities.

\section{CONCLUSION}

The preliminary results show that the suggested research protocol allows measuring of the average consumption of a firefighter department, brigade, or even a single firefighter in any part of Brazil using simple and doable procedures as long as the Fire Department has minimal equipment, such as the ones described in this paper.

This research opens a promising pathway, though it requires more scientific knowledge to give it a more scientific refinement by promoting its repeatability with samples from other Fire Departments. 


\section{ACKNOWLEDGMENTS}

The authors thank the command officers of the 1st Firefighters Brigade $-1^{\circ} \mathrm{GI}$, and the Physical Education and Sports Center, both part of the Pernambuco Military Fire Department, for their unconditional support, without which this research would have never been successful.

They also thank all the firefighters that voluntarily took the tests.

\section{REFERENCES}

[1]. CORRÊA, C. O Serviço de Combate a Incêndio no estado de Pernambuco, Brasil: do pioneirismo ao "embrião" institucional. 2 CILASCI - Congresso Ibero-Latino-Americano sobre Segurança contra Incêndio, Coimbra, 2013, p. 501- 505.

[2]. BRAGA, G.C.B; BRYNER, N.; MENSCH, A. Resistência à Radiação Térmica das Lentes dos Equipamentos de Proteção Respiratória Utilizada pelos Bombeiros: para onde podemos evoluir ? 2 CILASCI - Congresso Ibero-Latino-Americano sobre Segurança contra Incêndio, Coimbra, 2013, p. 507- 514.

[3]. GRANT, C.C. Respiratory Exposure Study for Fire Fighters and Other Emergency Responders. Fire Technology, v.46, p.497-529, 2010.

[4]. WEAKLEY, Jessica. Trends in respiratory diagnoses and symptoms of firefighters exposed to the World Trade Center disaster: 2005-2010. Preventive Medicine, v.53,p.364 -369, 2011.

[5]. LONNERMARK, A. Emission From an Automobile Fire. Chemosphere, v.62, p.1043-1056, 2006.

[6]. GALLAGHER, Michael; ROBERTSON, Robert; GOSS, Fredric; NAGLE, Elizabeth; SCHAFER, Mark; SUYAMA, Joe; HOSTLER, Davi. Development of a perceptual hyperthermia index to evaluate heat strain during treadmill exercise.European Journal of Applied Physiology, v.112, p.2025-2034, 2012.

[7]. TAYLOR, Nigel; LEWIS, Michael; NOTLEY, Sean; PEOPLES, Gregor. A fractionation of the physiological burden of the personal protective equipment worn by firefighters European Journal of Applied Physiology, v.112, p.2913-2921, 2012.

[8]. HARVEY, D.; KRAEMER, J.; SHARRATT, M.; HUGHSON, R.Respiratory gas exchange and physiological demands during a fire fighter evaluation circuit in men and women. European Journal of Applied Physiology, v.103, p.89-98, 2008.

[9]. HOLMÉR, Ingvar; GAVHED, Désirée. Classification of metabolic and respiratory demands in fire fighting activity with extreme workloads.Applied Ergonomics, v.38, p.45-52, 2007. 